\title{
Synthesis of Ion-Imprinted Polymer for Solid-Phase Extraction (IIP-SPE) of Lead from Tap Water Samples before ICP/OES Analysis: Compared to Monte Carlo simulation
}

\author{
Najmeh Sabbaghi ${ }^{1}$, Majid Monajjemi ${ }^{2, * \text { (D) }}$ \\ Department of Chemistry, Faculty of Science, Yazd University, Yazd 89195-741, Iran \\ Department of Chemical engineering, Science and Research Branch, Islamic Azad University, Tehran, Iran \\ * Correspondence: maj.monajjemi@iauctb.ac.ir (M.M.);
}

Scopus Author ID: 670181068

Received: 10.03.2021; Revised: 10.04.2021; Accepted: 14.04.2021; Published: 26.04.2021

\begin{abstract}
In this research, an ion-imprinted polymer (IIP) sorbent for lead ion has been synthesized to selective $\mathrm{Pb}$ extraction before the sensitive ICP/OES analysis. For this purpose, the lead complex was fabricated using $\mathrm{N}$-isoacrylamide as a monomer, ethylene glycol dimethacrylate as a crosslinker, and azobutyronitrile azobis as a primer. The product was examined by furrier transform infrared spectroscopy (FTIR) and scanning electron microscopy (SEM) techniques. The results show that the synthesized IIP has high efficiency in the adsorption of lead ions due to several suitable extraction sites (nitrogen and sulfur atoms) present in the polymer structure. Experimental evidence showed that the highest $\mathrm{Pb}$ ion uptake was at $\mathrm{pH}=6$. Also, $1 \mathrm{M}$ nitric acid solution in a volume of $5 \mathrm{~mL}$ has the highest amount of elution. Penetration volume for $\mathrm{Pb}$ from IIP-SPE was measured $50 \mathrm{~mL}$. The developed method was finally utilized to analyze $\mathrm{Pb}$ in various tap water samples, and the obtained results were compared with the standard method.
\end{abstract}

Keywords: ion-imprinted polymer; solid-phase extraction; lead; tap water; ICP/OES; Monte Carlo simulation.

(C) 2021 by the authors. This article is an open-access article distributed under the terms and conditions of the Creative Commons Attribution (CC BY) license (https://creativecommons.org/licenses/by/4.0/).

\section{Introduction}

In recent decades, much attention has been focused on investigating heavy metal concentrations in water samples due to the toxicity, bioavailability, and environmental behavior of metal ions [1-5]. Lead is one of the heavy metals in the periodic table in the fourteenth and sixth periods. Lead is the second most widely used industrial metal after iron. Most of the lead in the environment is emitted from vehicles. The source of almost all lead tetra alkyls is from the evaporation of gasoline. These compounds do not dissolve in water but are absorbed through the skin. Airborne lead oxide eventually settles on the ground, water, fruits, or leafy vegetables and enters the food chain. Most of the lead that enters the human body enters the bloodstream, eventually reaches a constant level, and excess lead enters soft tissues, especially the brain. Finally, lead builds up in the bone marrow and replaces calcium due to the similar size. Biochemically, lead interferes with hemoglobin production by interfering with the work of enzymes and causes anemia by lowering hemoglobin levels. Fetuses and children under the age of seven are vulnerable even to low levels of lead. This metal passes through the fetal placenta, enters the fetal body, and causes abortion or the fetus's premature birth. In children, 
it prevents the brain's normal development and has harmful effects on them [6,7]. In 1996, the World Health Organization (WHO) limited the concentration of lead in drinking water to 0.01 $\mu \mathrm{g} \mathrm{L}^{-1}[8]$. Due to the serious concern caused to humans' health by heavy metals, even at low concentrations, the separation and determination of these substances from water and the environmental samples is a major challenge. So far, various methods have been used to measure heavy metals from water. Except for the adsorption method, most of these methods are cost-oriented and are not suitable for separating metal ions at low concentrations. IIP is a new method to separate, remove, and extract $\mathrm{Pb}$ from water [9-12]. This method, with its high selectivity, is very suitable for absorbing heavy metal ions. The most important advantages of the separation method with IIPs are the simplicity of the preparation method, cheapness, effective efficiency in extracting low ion concentrations, and high adsorption speed. These polymers have high mechanical stability due to their high cross-linking and can be reused $[13,14]$. Analysis of metals after pretreatment and extraction can be assayed with various analytical techniques, such as atomic absorption spectroscopy (AAS) [15,16], inductively coupled plasma (ICP) with a different detector, including atomic emission spectroscopy (AES) [17, 18], mass spectrometry (MS) [19-21] and optical emission spectrometry (OES) [22-26], atomic fluorescence spectrometry, X-ray fluorescence spectrometry, neutron activation analysis, liquid chromatography, and electrochemical methods, which ICP methods have many advantages in comparison with other analysis techniques. It has the same or better detection limits for most of the elements, higher throughput, the ability to handle both simple and complex matrices with a minimum of matrix interferences on account of the high temperature of the ICP source [27-31].

In this study, a new adsorbent with very high adsorption power based on IIP for selective solid-phase extraction of lead ion using $\mathrm{N}$-isoacrylamide monomer, ethylene glycol dimethacrylate cross-linking agent, and azobutyronitrile azobis as an initiator was synthesized. This polymer as a solid phase extraction (SPE) sorbent was used to preconcentrate lead from water samples. The selectivity of IIP for lead ions was evaluated, and its results were compared with NIP (non-imprinted polymer) sorbent that provides information about the IIP imprinting effect and selectivity. Also, the real sample analysis results by IIP-SPE/ICP-OES were compared statistically with the AAS method as a standard method [32-40].

\section{Materials and Methods}

\subsection{Materials.}

$\mathrm{N}$-isopropyl acrylamide with a purity of $98 \%$ was purchased from Aldrich Company (Germany). Lead nitrate salt, acetonitrile, ethyl acetate, ethanol, methanol, and benzene solvents with high purity were purchased from Merck (Germany). Ethylene glycol dimethacrylate and also azobisisobutyronitrile (AIBN) as a primer in the polymerization process were bought from Acros Organic Company ( New Jersey, USA).

\subsection{Instrumentation.}

WQF-510A FTIR spectroscopy (furrier transform infrared spectroscopy) was used to identify the complex functional groups using the KBR tablet sampling method with a pressure of 20 Bar. The scanning range of the spectrum was from $400-4000 \mathrm{~cm}^{-1}$. ICP-OES 735ES made by VARIYAN Company was used to measure the absorption of lead. Also, to study IIP 
and NIP morphology, the FE-SEM (Field Emission Scanning Electron Microscopy) EIGMA/VD instrument ( Zeiss company Germany) was used

\subsection{Synthesis of IIP and NIP.}

First, $0.332 \mathrm{~g}$ of $\mathrm{Pb}\left(\mathrm{NO}_{3}\right)_{2}$ was dissolved in $5 \mathrm{~mL}$ deionized water (DW). In another beaker, $2 \mathrm{mmol}$ of monomer (N-isoacrylamide agent) was dissolved in $5 \mathrm{~mL} \mathrm{DW}$. It was then gently added to the $\mathrm{Pb}$ solution. The mixture was stirred for $3 \mathrm{~h}$ at room temperature. After this time, $5.39 \mathrm{~g}$ ethylene glycol dimethacrylate crosslinker and $0.1 \mathrm{~g}$ azobisisobutyronitrile initiator and $50 \mathrm{~mL}$ ethanol were added to the obtained complex solution and was heated for $2 \mathrm{~h}$ at 25 ${ }^{\circ} \mathrm{C}$ under the stirring condition. It should be noted that deoxygenation is necessary during the polymerization process because oxygen traps the produced radicals and prevents the polymerization process, so to remove oxygen, the flow of Ar was blown into the solution for $15 \mathrm{~min}$. The reaction vessel was then sealed and placed in an oil bath at $60{ }^{\circ} \mathrm{C}$ for $24 \mathrm{~h}$. The formed polymer was first washed with ethanol to remove unreacted monomers. It was then washed several times with $\mathrm{HCl}$ : ethanol (1:1) to remove imprinted ions. Finally, it was washed several times with distilled water and dried in an oven at $60{ }^{\circ} \mathrm{C}$. NIP was synthesized in the same way, but $\mathrm{Pb}$ ions were not used.

\subsection{IIP-SPE/ICP/OES procedure.}

To prepare the SPE column, $0.5 \mathrm{~g}$ of prepared polymer fill into a polypropylene cartridge. To prevent from releasing the stationary phase, both ends of the sorbent were kept by porous polyethylene plates with a thickness of $200 \mu \mathrm{m} .10 \mathrm{~mL}$ of Pb solution or real water samples were passed through the column. The column was then washed with $5 \mathrm{~mL}$ of nitric acid $(1 \mathrm{M})$ as the desorption solvent to extract the adsorbed $\mathrm{Pb}$ from the IIP structure. Since the volume of solvent required for a complete washing of the analytes is much less than the original sample volume, a concentrated sample of the analytes is obtained, and this extracted solution was injected into the ICP/OES.

\subsection{Simulation Methodology.}

The interactions N-Iso-acrylamide as a monomer, ethylene glycol di-methacrylate as a crosslinker, and Iso-butyronitrile azobis as a primer with $\mathrm{Pb}$ are estimated via Lenard-Jones potentials as follows: $V_{L J}\left(r_{i j}\right)=4 \varepsilon_{i j}\left\{\left[\left(\frac{\sigma_{i j}}{r_{i j}}\right)^{12}-\left(\frac{\sigma_{i j}}{r_{i j}}\right)^{6}\right]\right\}, r<R_{C}(\mathbf{8}), R_{C}$ is a cutoff distance around $12 \AA$ for VE. In addition the Lorentz-Berthelot rules have been applied for the inter forces among $\mathrm{VE}$ and graphene atoms as follows " $\sigma_{i j}=0.5\left(\sigma_{i}+\sigma_{j}\right)$ "and $\varepsilon_{i j}=\sqrt{\varepsilon_{i}} * \sqrt{\varepsilon_{j}}$. (9). the non-bonded and bonded data, including van der Waals of related force fields are listed in Tables1\&2. The total energies of the model systems are a total of several partial energies as follows: $E_{\text {(system) }}=\mathrm{E}_{\text {(bond) }}+\mathrm{E}_{\text {(angle) }}+\mathrm{E}_{\text {(torsion) }}+\mathrm{E}_{\text {(over) }}+\mathrm{E}_{(\mathrm{vdW})}+\mathrm{E}_{\text {(Coulomb) }}+\mathrm{E}_{\text {(Specific) }}$, (10), where $\mathrm{E}_{\text {(bond) }}$ and $\left(\mathrm{E}_{(\text {angle })}+\mathrm{E}_{\text {(torsion) }}\right)$ are bond formation and angle (both strain and torsional) energies, respectively. $\mathrm{E}_{\text {(over) }}$ is associated with valence and torsional angles, respectively that prevents

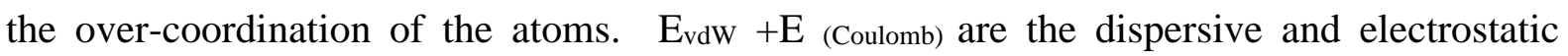
energies contribution between all atoms, respectively. Finally, $\mathrm{E}_{\text {(Specific) }}$ is a system-specific energies such as lone-pair, conjugation and hydrogen bonding. 
Table 1. Non-bonded parameters in terms of $E_{(\text {van der waals) }}+E_{\text {(Coulomb). }}$

\begin{tabular}{lccc}
\hline \multicolumn{3}{c}{ Non bonded interaction } \\
\hline Atom type & $V_{L J}\left(r_{i j}\right)=4 \varepsilon_{i j}\left\{\left[\left(\frac{\sigma_{i j}}{r_{i j}}\right)^{12}-\left(\frac{\sigma_{i j}}{r_{i j}}\right)^{6}\right]\right\}, r<R_{C}$ & \\
CH2 & Mass $(\mathbf{g} / \mathbf{m o l})$ & $\boldsymbol{\sigma}(\mathbf{n m})$ & $\boldsymbol{\varepsilon}\left(\frac{\boldsymbol{k c a l}}{\boldsymbol{m o l}}\right)$ \\
C=O & & 0.396 & 0.0 .091 \\
O-H & 14.03 & 0.435 & 0.109 \\
C-O & 28.05 & 0.223 & 0.024 \\
C-C & 17.08 & 0.412 & 0.102 \\
N-C & 28.07 & 0.123 & 0.072 \\
& 24.03 & 0.446 & 0.055
\end{tabular}

Table 2. Parameters of bonded interactions of the atomistic force field.

\begin{tabular}{|c|c|c|c|c|c|c|c|c|c|}
\hline & $\left\{\left[V_{b}(r\right.\right.$ & $=\sum_{\text {bond }}$ & $\begin{array}{l}{ }_{i j}^{b}\left(r_{i j}\right. \\
0.5 \sum_{\text {angl }}\end{array}$ & $\begin{array}{l}\text { led \& } \\
]\}+\{[ \\
\theta_{i j k}-\end{array}$ & $\begin{array}{l}\text { e interactior } \\
\left.\theta_{i j k}\right) \\
\left.\left.)^{2}\right]\right\}+\{[V(\end{array}$ & $\left.k_{k l}\right) k_{\varphi}($ & $\operatorname{Cos}(r$ & $-\delta$ & \\
\hline bond & $b(\AA)$ & \begin{tabular}{l}
\multicolumn{1}{c}{$k^{b}$} \\
$\mathrm{kcal} / \mathrm{mol}^{*}$ \\
$\AA^{2}$
\end{tabular} & angle & $\theta_{i j k}^{0}$ & $\begin{array}{c}k_{i j k}^{\theta} \\
\left(\frac{\mathrm{kcal}}{m o l} * \operatorname{Rad}^{2}\right)\end{array}$ & $\begin{array}{c}\text { Dihedral } \\
\varphi_{i j k l}\end{array}$ & \begin{tabular}{l}
\multicolumn{1}{c}{$k_{\varphi}$} \\
$\mathrm{kcal} / \mathrm{mo}$ \\
1
\end{tabular} & $n$ & $\delta$ \\
\hline $\mathrm{C}-\mathrm{H}$ & 1.11 & 330 & C-O-C & 117.2 & 53.1 & C-C-C & & 1 & 0.00 \\
\hline $\mathrm{C}=\mathrm{O}$ & 1.21 & 340 & C-C-C & 122.1 & 65.9 & H-C-C-C & 0.400 & 3 & 180.0 \\
\hline $\mathrm{O}-\mathrm{H}$ & & 360 & O-C-O & 119.4 & 45.3 & $\mathrm{O}-\mathrm{C}-\mathrm{C}-\mathrm{H}$ & 0.25 & 2 & 0.00 \\
\hline C-O & 1.41 & 230 & C-C-H & 110.1 & 46.5 & $\mathrm{C}-\mathrm{O}-\mathrm{C}-\mathrm{H}$ & 0.5 & 2 & 0.00 \\
\hline C-C & & 440 & H-C-H & 107.2 & & H-C-C-H & 0.32 & 1 & 180.0 \\
\hline $\mathrm{C}=\mathrm{C}$ & 1.34 & 365 & $\mathrm{O}-\mathrm{C}-\mathrm{H}$ & 108.2 & 44.7 & $\mathrm{O}-\mathrm{C}-\mathrm{C}-\mathrm{O}$ & 0.64 & 3 & 0.00 \\
\hline
\end{tabular}

The TIP3 model uses a total of the three sites for the electrostatic interactions. The partial positive charges on the hydrogen atoms are exactly balanced by an appropriate negative charge located on the oxygen atom. The OPLS model is a modified form of TIPS that has parameters fitted to liquid state properties and more suitable for liquids studies. The model works well for various alcohols, amines, aliphatic and aromatic hydrocarbons, sulfur compounds, ether, amino acids, and nucleic acid bases. The OPLS Lennard-Jones parameters for nucleic acid bases are included in Table 3.

Table 3. OPLS Lennard-Jones parameters for nucleic acid bases.

\begin{tabular}{l|l|l} 
Atom & \multicolumn{1}{|c|}{$\sigma, \AA$} & \multicolumn{1}{|c}{$\varepsilon, \mathrm{kcal} / \mathrm{mol}$} \\
\hline $\mathrm{O}$ & 2.95 & 0.205 \\
\hline $\mathrm{N}$ & 3,21 & 0.165 \\
\hline $\mathrm{C}$ in $\mathrm{C}=\mathrm{O}$ & 3.8 & 0.110 \\
\hline $\mathrm{C}$ normal & 3.5 & 0.085 \\
\hline $\mathrm{H}(\mathrm{N})$ & 0.0 & 0.0 \\
\hline $\mathrm{H}(\mathrm{C})$ & 2.25 & 0.07 \\
\hline $\mathrm{H}(\mathrm{O})$ & 1.95 & 0.05
\end{tabular}

In the second section of our research, calculations were performed with the simulation program CHARMM. An empirical energy function that contains terms of both internal and external interactions was used. All modeling and simulation details have been done based on our previous works [41-58]. 


\section{Results and Discussion}

\subsection{Characterization.}

To investigate the surface structure and particle size of the synthesized IIP, the SEM method was used [59-69]. The result (Figure 1) approved the sediment polymerization method's success in obtaining IIP particles with a spherical structure in the nanoscale range (200-1000nm).

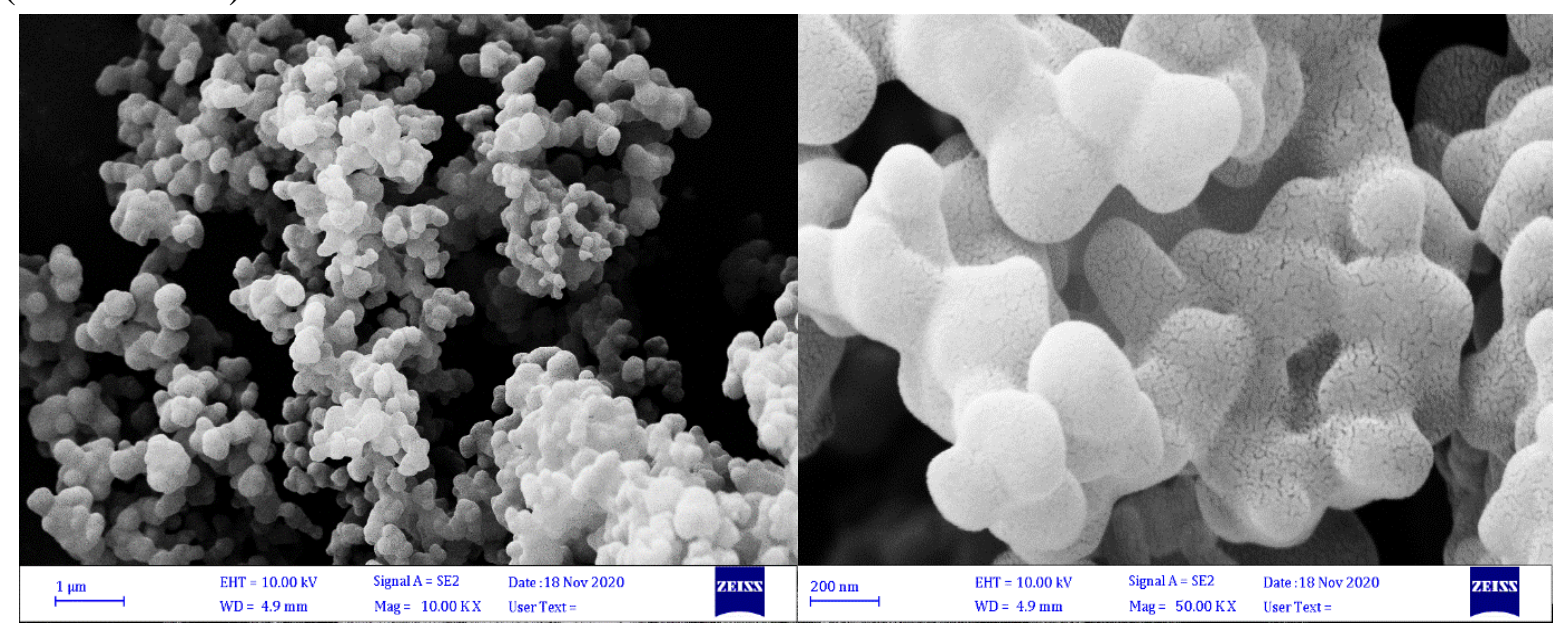

Figure 1. SEM images of synthesized IIP.

Investigation of FTIR spectra of ligand, IIP, and NIP (Figure 2) complex show the change of P-O-M adsorption region, which means that the metal reacts with the ligand. On the other hand, the shift in the ligand's vinyl bond indicates that the metal did not react with the $\mathrm{C}=\mathrm{C}$ of the ligand. Other vibration peaks can be identified as follow: 3299 (N-H stretching), 3284 (N-H bending), 3072 (amides' N-H stretching), $2970\left(\mathrm{CH}_{3}\right.$ stretching), 1920-1935 (unsaturated amide stretching), 1657 ( $\mathrm{C}=\mathrm{O}$ stretching), 1622 (alkene stretching), $1548(\mathrm{~N}-\mathrm{H}$ bending), 1410 (terminal vinyl bending), 1140-1171 $\left(\mathrm{CH}_{3}\right)$ and 840-965 $\left(=\mathrm{CH}_{2}\right.$ stretching).

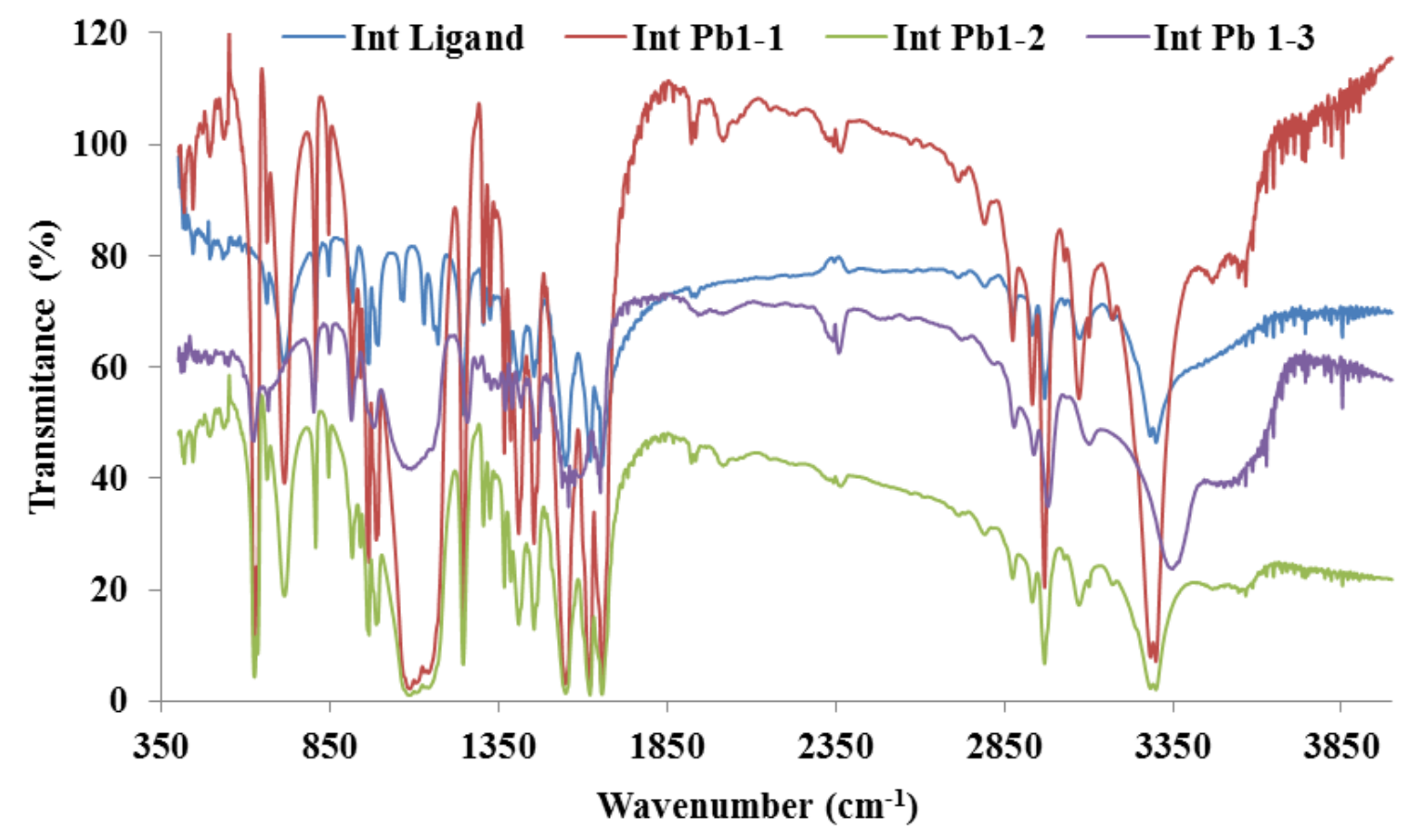

Figure 2. FTIR spectra of synthesized IIP. 


\subsection{Optimization of effective parameters on the Pb adsorption in the IIP-SPE column.}

To optimize the amount of $\mathrm{Pb}$ ion adsorption by the IIP-SPE column, some important parameters such as the effect of $\mathrm{pH}$, appropriate concentration of elution, the amount of penetration volume, and the effect of imprinting were studied.

\subsubsection{Effect of solution $\mathrm{pH}$.}

$\mathrm{pH}$ is an example of an important and effective parameter in the process of adsorption of various compounds by IIP, the optimal value of which depends on the adsorbent's chemical structure and the desired analyte and their structure changes with $\mathrm{pH}$ change. To investigate the effect of $\mathrm{pH}$, first solutions with a concentration of $500 \mathrm{ppb}$ were prepared from the $\mathrm{Pb}$ salt with different $\mathrm{pHs}$, and $10 \mathrm{~mL}$ of these solutions were passed through the cartridge. The output phase was collected, and ICP-OES analyzed its lead content. As can be seen (Figure 3), at pH 2 to 4 , it is due to the acidic environment, and the concentration of protons is high and competes with $\mathrm{Pb}$ to penetrate into the polymer and greatly reduces the amount of adsorption and the highest percentage of adsorption uptake by IIP was obtained in $\mathrm{pH}=6$. It seems that in acidic and alkaline $\mathrm{pHs}$, the occurrence of the process of hydrolysis of functional groups reduces the ability of adsorption by IIP. Therefore, $\mathrm{pH}=6$ was considered as the optimal value in subsequent experiments.

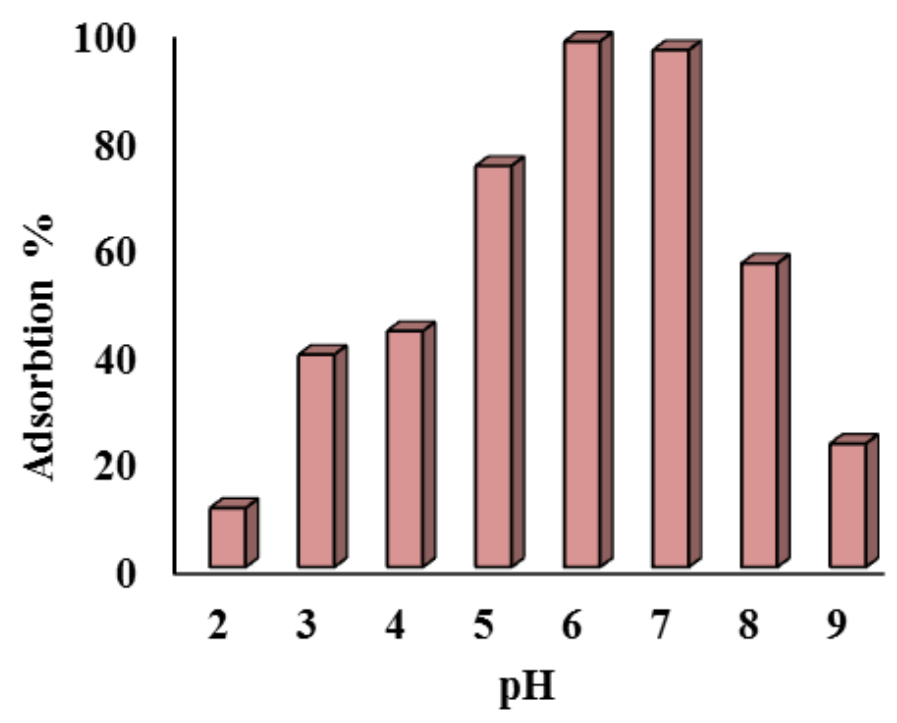

Figure 3. Effect of solution $\mathrm{pH}$ on the adsorption efficiency, condition: $10 \mathrm{~mL} \mathrm{~Pb}{ }^{2+}$ solution with concentration: $500 \mu \mathrm{g} \mathrm{L}^{-1}$, sorbent weight: $0.5 \mathrm{~g}$, eluent: $\mathrm{HNO}_{3}$, volume of eluent: $5 \mathrm{~mL}$, concentration of eluent: $1 \mathrm{M}$.

3.2.2. Determination of suitable concentration of nitric acid for $\mathrm{Pb}$ desorption from IIP adsorbent.

To determine the appropriate concentration of nitric acid for elution and extraction of $\mathrm{Pb}$ ions from the cartridge, $5 \mathrm{~mL}$ nitric acid solutions with different concentrations of $0.05,0.1$, 0.5 , and $1 \mathrm{M}$ were passed after column loading by $10 \mathrm{~mL}$ working solution. Finally, the output of the column was collected and its $\mathrm{Pb}$ content was measured by ICP-OES. Based on the results (Figure 4), the concentration that has removed the largest amount of lead from the column is more suitable for washing, which is equal to $1 \mathrm{M}$. Because the same concentration of $1 \mathrm{M}$ removed all the $\mathrm{Pb}$ (the amount that remains is a random error). On the other hand, the more concentrated the acid, the greater the environmental risk. 


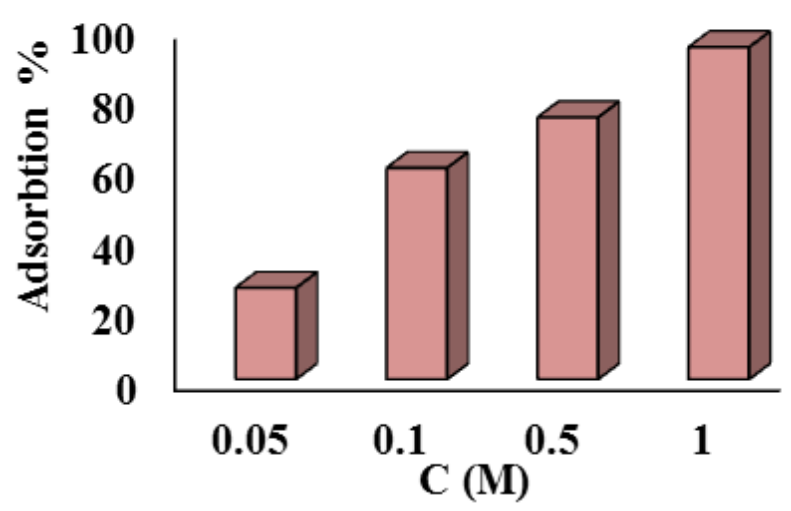

Figure 4. Effect of eluent concentration on the adsorption efficiency, condition: $10 \mathrm{~mL} \mathrm{~Pb}^{2+}$ solution with concentration $500 \mu \mathrm{g} \mathrm{L}^{-1}$, sorbent weight: $0.5 \mathrm{~g}$, eluent: $\mathrm{HNO}_{3}$, volume of eluent: $5 \mathrm{~mL}$.

\subsubsection{Determination of penetration volume of IIP-SPE column.}

To determine the column's appropriate penetration volume based on the World Health Organization (WHO) standard, a $2 \mathrm{~mL}$ standard solution with a concentration of $500 \mathrm{ppb}$ was used. Then, in volumes of 10, 50, and $100 \mathrm{~mL}$ with a 200, 40 and $20 \mathrm{ppb}$ concentration, they were prepared at optimal $\mathrm{pH}$. The concentration of the solutions before and after the passing through the column were analyzed by ICP-OES. It should be noted that after passing the solution, the column should be thoroughly washed with $1 \mathrm{M}$ nitric acid and distilled water. The column's appropriate penetration volume can be calculated if $10 \%$ of the concentration of the initial solution comes out of the column. Based on the results, the penetration volume for the $\mathrm{Pb}$-IIP column was $50 \mathrm{~mL}$.

\subsubsection{The effect of imprinting of $\mathrm{Pb}$ in IIP polymer its comparison with control polymer.}

To determine the IIP column's adsorption, a control polymer was made without the presence of $\mathrm{Pb}$ (named NIP) for comparison with IIP. Examination of the results obtained from the imprinting effect of IIP and NIP showed that IIP, due to the presence of cavities formed in proportion to the size and radius of the $\mathrm{Pb}$ ion, is highly inclined to $\mathrm{Pb}$ ion. This metal is trapped in cavities whose size and shape are the same as the iconic shape and radius of $\mathrm{Pb}$, and according to the results of ICP-OES analysis, it is shown that the IIP column has much higher adsorption than NIP (Table 1).

Table 1. Comparison of IIP and NIP in Pb adsorption.

\begin{tabular}{c|c|c|c} 
Sorbent & $\mathbf{C}_{\text {initioal }}\left(\boldsymbol{\mu} \mathbf{g ~ L}^{-\mathbf{1}}\right)$ & $\mathbf{C}_{\text {final }}\left(\boldsymbol{\mu} \mathbf{g ~ L}^{\mathbf{- 1}}\right)$ & Adsorbtion \% \\
\hline IIP & 500 & 32.4 & $\mathbf{9 3 . 5 2 \%}$ \\
\cline { 1 - 3 } NIP & & 321.1 & $\mathbf{3 5 . 7 8 \%}$
\end{tabular}

\subsection{Interfering study and selectivity of developed IIP.}

To investigate the disturbance effect, the aqueous sample was intentionally contaminated with alkaline and alkaline earth elements, and the amount of lead ion adsorption in the presence of these disturbing ions was measured by the polymer.

As shown in Table 2, high concentrations of magnesium and cadmium ions do not interfere with lead extraction, indicating the prepared IIP column's high selectivity relative to lead ions. But in the case of $\mathrm{Na}$, due to its small size and ability to fill the cavities, the adsorption of $\mathrm{Pb}$ was dramatically decreased. 
Therefore, the closer the atomic radius is to lead, the higher the absorption interference. So some of the absorptions is related to physical absorption

Table 2. Interfering study.

\begin{tabular}{|c|c|c|c|}
\hline Cation & $C_{\text {initioal }}\left(\mu \mathrm{g} \mathrm{L}^{-1}\right)$ & $C_{\text {final }}\left(\mu g L^{-1}\right)$ & Adsorbtion \% \\
\hline $\mathrm{Pb}$ & \multirow[t]{4}{*}{500} & 49 & $90.2 \%$ \\
\hline $\mathrm{Mg}$ & & 102 & $79.6 \%$ \\
\hline $\mathrm{Cd}$ & & 138 & $72.4 \%$ \\
\hline $\mathrm{Na}$ & & 387 & $22.6 \%$ \\
\hline
\end{tabular}

\subsection{Real sample analysis and comparison with the standard method.}

$40 \mathrm{~mL}$ (proportional to the penetration volume) of tap water samples after $\mathrm{pH}$ adjustment without any other treatment was used to determine the concentration of $\mathrm{Pb}$ by developed IIP-SPE extraction followed by ICP-OES. Then $5 \mathrm{~mL}$ of $1 \mathrm{M}$ nitric acid was passed through the column for washing of extracted ions. By doing this, the pre-concentrated samples were obtained and their concentration reaches the detection limit of the ICP-OES device. The results of the method are given in Table 3. As can be seen, the results of ICP-OES in all three samples of urban water have good repeatability.

Table 3. Real sample analysis with the developed method.

\begin{tabular}{c|c|c|c|c}
\multirow{2}{*}{ Sample } & \multicolumn{2}{|c}{ ICP-OES } & \multicolumn{3}{c}{ ICP-OES (after elimination) } \\
\cline { 2 - 5 } & $\mathbf{C}_{\text {found }}\left(\boldsymbol{\mu g} \mathbf{L}^{-1}\right)$ & $\mathbf{R S D} \%$ & $\mathbf{C}_{\text {found }}\left(\boldsymbol{\mu g} \mathbf{L}^{-\mathbf{1}}\right)$ & $\mathrm{RSD} \%$ \\
\hline Tap water 1 (Karaj) & 43.4 & 3.6 & 3.0 & 2.6 \\
\hline Tap water 1 (Tehran) & 53.3 & 3.2 & 2.2 & 2.9 \\
\hline Tap water 1 (Rasht) & 23.5 & 3.0 & 0.58 & 3.1
\end{tabular}

\subsection{Molecular dynamic root section}

Given an auto-polymerization tendency N-mono- and di-substituted hydroxyalkyl(meth)acrylamides as an alternative in electrophoresis gels have been applied. The formula of the monomers is shown in scheme 1 .

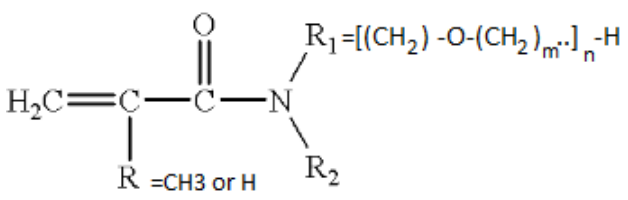<smiles>C=CC(=O)NCCO</smiles><smiles>C=CC(=O)OCCN</smiles><smiles>C=CC(=O)NCCOC(=O)C=C</smiles>

Scheme 1. Various hydrophilic monomers.

For capillary electrophoresis (CE) of biological molecules, linear non-crosslinked polymers are commonly used rather than cross-linked gels due to the easy replacement of media between runs. Many water-soluble, non-ionic polymers were shown to have utility as sieving media for CE. CG models of various hydrophilic monomers polymer chains are composed of "beads" with each bead representing some portion of the polymer chains. The length scale of the mapping between full atomistic detail and a CG bead can vary wildly, and this mapping is one of the key choices made in choosing/developing an appropriate CG model. CG beads can represent a specific group of atoms within a monomer, a group of monomers on the length scale of a Kuhn segment, a group of Kuhn segments, or even the whole chain, in addition, the CNMR amount of atoms have been used for atomic models in the dynamic and Monte-Carlo 
simulation (Figure 5). Due to atomistic models, length scales might be shorter than the standard contour lengths of polymer chains ( $>50$ ) repeat units, long time scale relaxation of a single chain and/or rearrangement of many such polymer chains during an atomistic simulation is out of the range.
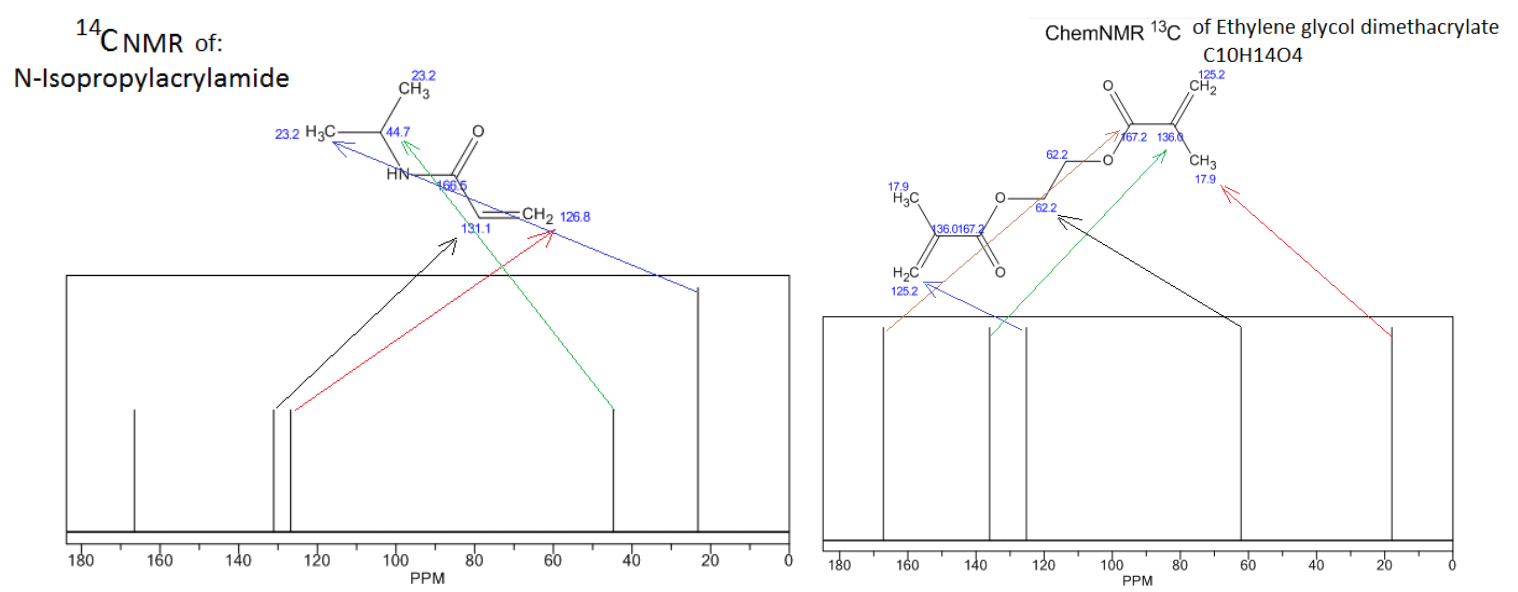

Figure 5. CNMR of N-Iso-acrylamide as a monomer, ethylene glycol di-methacrylate as a crosslinker for dynamic simulation.

In these lattice models, used primarily with Monte Carlo (MC) simulations, each CG bead in a polymer is placed on a lattice site with the bonded neighboring CG bead placed on one of the nearest/next-nearest-neighbor sites on that lattice. The cubic 3D lattice has been used in most studies, while face-centered (3D) and square (2D) lattices have been used less frequently. The pressures were maintained through the variant of advanced systems formalism and also the Langevin Piston algorithm, which decreases oscillations in those cells parameters. The temperatures were fixed between $300 \mathrm{~K}$ to $310 \mathrm{~K}$, where are the biological ranges and identical to the relevant experiments. The configuration of individual monomer consistent with a mean field was generated by the Monte Carlo (MC) simulation, with field values adjusted for obtaining acceptable experimental order data. NVT (stands for a constant number of atoms, volume, and temperature) is the thermodynamic ensemble used via the entire simulation. Dynamic time for atomic modeled is proportional to the number of units included in each supercell. A dynamic step of $0.1 \mathrm{fs}$ with simulation temperature equal=300 has been done by Hyper-Chemistry software. The choice of the lattice and type of lattice model dictates the distribution of bond lengths and bond angles (Tables 1-3). The interaction potentials between the no-bonded polymers beads are modeled through hard-sphere interaction potential or single/multiple square well potentials (Figure 6).

\section{Conclusions}

Heavy metal pollution is a major environmental problem, and even small amounts are harmful to human health. Therefore, monitoring these metals in water and environmental samples is an important challenge. The use of IIP sorbents causes increases selectivity in metal ion extraction. Considering this feature in this paper, an IIP was prepared for lead metal and it was used to SPE of lead from tap water samples. In the optimal conditions of the extraction, the adsorption of $\mathrm{Pb}$ on the IIP was more than $90 \%$. The ability to produce IIPs on a larger scale due to less expensive commercial monomers required for its production and the possibility of reusing the adsorbent can make this method one of the most important methods 
for monitoring heavy metals on an industrial scale. It is notable that, Monte-Carlo simulation might be useful for further investigation of these kinds of approaches.
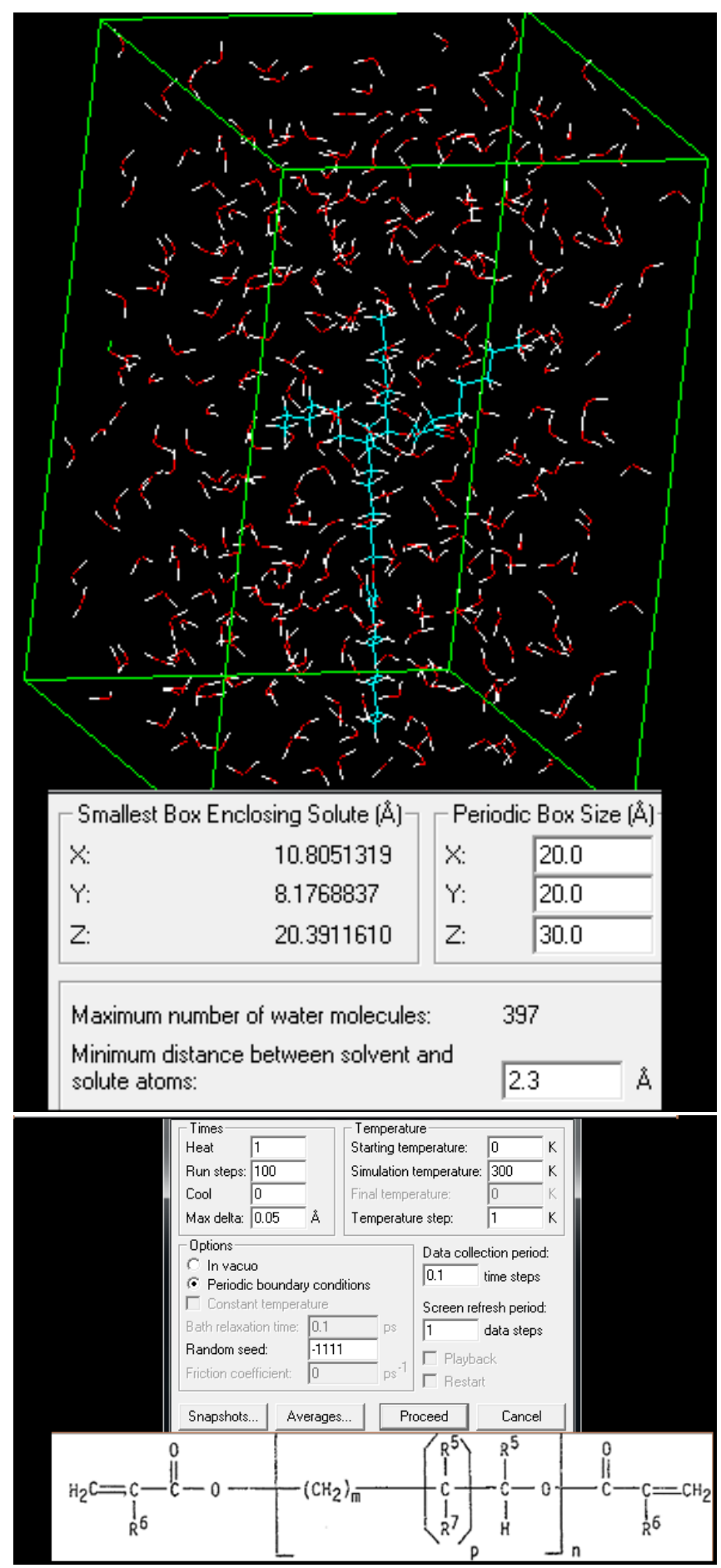

Figure 6. Simulated polymer in a water box.

\section{Funding}

This research received no external funding.

\section{Acknowledgments}

The authors thanks Yazd University for providing lab instrument, materials, equipment and other facilities. 


\section{Conflicts of Interest}

The authors declare no conflict of interest.

\section{References}

1. Manousi, N.; Gomez-Gomez, B.; Madrid, Y.; Deliyanni, E.A.; Zachariadis, G.A. Determination of rare earth elements by inductively coupled plasma-mass spectrometry after dispersive solid phase extraction with novel oxidized graphene oxide and optimization with response surface methodology and central composite design. Microchem. J. 2020, 152, 104428, https://doi.org/10.1016/j.microc.2019.104428.

2. Gonçalves, L.M. Electropolymerized molecularly imprinted polymers: Perceptions based on recent literature for soon-to-be world-class scientists. Curr. Opin. Electrochem. 2021, 25, 100640, https://doi.org/10.1016/j.coelec.2020.09.007.

3. Dahaghin, Z.; Kilmartin, P.A.; Mousavi, H.Z. Novel ion imprinted polymer electrochemical sensor for the selective detection of lead(II). Food Chem. 2020, 303, 125374, https://doi.org/10.1016/j.foodchem.2019.125374.

4. Jakavula, S.; Biata, N.R.; Dimpe, K.M.; Pakade, V.E.; Nomngongo, P.N. A critical review on the synthesis and application of ion-imprinted polymers for selective preconcentration, speciation, removal and determination of trace and essential metals from different matrices. Crit. Rev. Anal. Chem. 2020, 1-13, https://doi.org/10.1080/10408347.2020.1798210.

5. Krishna,M.B.; Chandrasekaran, K.; Rao, S.V.; Karunasagar, D.; Arunachalam, J. Speciation of Cr(III) and $\mathrm{Cr}(\mathrm{VI})$ in waters using immobilized moss and determination by ICP-MS and FAAS. Talanta 2005, 65, 135143, https://doi.org/10.1016/j.talanta.2004.05.051.

6. Alizadeh, T.; Amjadi, S. Preparation of nano-sized $\mathrm{Pb}^{2+}$ imprinted polymer and its application as the chemical interface of an electrochemical sensor for toxic lead determination in different real samples. Journal of hazardous materials 2011, 190, 451-459, https://doi.org/10.1016/j.jhazmat.2011.03.067.

7. Jinadasa, K.K.; Peña-Vázquez, E.; Bermejo-Barrera, P.; Moreda-Piñeiro, A. New adsorbents based on imprinted polymers and composite nanomaterials for arsenic and mercury screening/speciation: A review. Microchem. J. 2020, 156, 104886, https://doi.org/10.1016/j.microc.2020.104886.

8. Zhang, Z.; Li, M.; Chen, W.; Zhu, S.; Liu, N.; Zhu, L. Immobilization of lead and cadmium from aqueous solution and contaminated sediment using nano-hydroxyapatite. Environmental Pollution 2010, 158, 514519, https://doi.org/10.1016/j.envpol.2009.08.024.

9. Jinadasa, K.K.; Herbello-Hermelo, P.; Peña-Vázquez, E.; Bermejo-Barrera, P.; Moreda-Piñeiro, A. Mercury speciation in edible seaweed by liquid chromatography-Inductively coupled plasma mass spectrometry after ionic imprinted polymer-solid phase extraction. Talanta 2020, 224, 121841, https://doi.org/10.1016/j.talanta.2020.121841.

10. Marc, M.; Wieczorek, P.P. The preparation and evaluation of core-shell magnetic dummy-template molecularlyimprinted polymers for preliminary recognition of the low-mass polybrominated diphenyl ethers from aqueous solutions. Sci. Total Environ. 2020, 724, 138151, https://doi.org/10.1016/j.scitotenv.2020.138151.

11. Adauto, A.; Khan, S.; Augusto da Silva, M.; Gomes Neto, J.A.; Picasso, G.; Sotomayor, M.d.P.T. Synthesis, characterization and application of a novel ion hybrid imprinted polymer to adsorb Cd(II) in different samples. Environ. Res. 2020, 187, 109669, https://doi.org/10.1016/j.envres.2020.109669.

12. Aboufazeli, F.; Zhad, H. R. L. Z.; Sadeghi, O.; Karimi, M.; Najafi, E. Novel ion imprinted polymer magnetic mesoporous silica nano-particles for selective separation and determination of lead ions in food samples. Food Chemistry 2013, 141, 3459-3465, https://doi.org/10.1016/j.foodchem.2013.06.062.

13. Sayar, O.; Torbati, N.A.; Saravani, H.; Mehrani, K.; Behbahani, A.; Zadeh, H. R. M. A novel magnetic ion imprinted polymer for selective adsorption of trace amounts of lead(II) ions in environment samples. Journal of Industrial and Engineering Chemistry 2014, 20, 2657-2662, https://doi.org/10.1016/j.jiec.2013.10.052.

14. Guo, B.; Deng, F.; Zhao, Y.; Luo, X.; Luo, S.; Au, C. Magnetic ion-imprinted and -SH functionalized polymer for selective removal of $\mathrm{Pb}$ (II) from aqueous samples. Applied surface science 2014, 292, 438-446, https://doi.org/10.1016/j.apsusc.2013.11.156.

15. Ebrahimzadeh, H.; Asgharinezhad, A. A.; Moazzen, E.; Amini, M.M.; Sadeghi, O. A magnetic ion-imprinted polymer for lead(II) determination: A study on the adsorption of lead(II) by beverages. Journal of Food Composition and Analysis 2015, 41, 74-80, https://doi.org/10.1016/j.jfca.2015.02.001.

16. Safari, M.; Shojaei, S.; Tehrani, P.; Karimi, A. A patient-specific finite element analysis of the anterior cruciate ligament under different flexion angles, Journal of Back and Musculoskeletal Rehabilitation, 2020, 33(5), pp. 811-815

17. Fayazi, M.; Taher, M.A.; Afzali, D.; Mostafavi, A.; Ghanei-Motlagh, M. Synthesis and application of novel ion-imprinted polymer coated magnetic multi-walled carbon nanotubes for selective solid phase extraction 
of lead(II) ions. Materials Science and Engineering: C 2016, 60, 365-373, https://doi.org/10.1016/j.msec.2015.11.060.

18. Özkara,S.; Andaç, M.; Karakoç, V.; Say, R.; Denizli, A. Ion-imprinted PHEMA based monolith for the removal of $\mathrm{Fe}^{3+}$ ions from aqueous solutions. Journal of applied polymer science 2011, 120, 1829-1836, https://doi.org/10.1002/app.33400.

19. Yıldız, E.; Saçmacı, S.; Kartal, S.; Saçmacı, M. A new chelating reagent and application for coprecipitation of some metals in food samples by FAAS. Food chemistry, 2016, 194, 143-148, https://doi.org/10.1016/j.foodchem.2015.07.084.

20. de Oliveira, R.M.; Antunes, A.C.N.; Vieira, M.A.; Medina, A.L.; Ribeiro, A.S. Evaluation of sample preparation methods for the determination of $\mathrm{As}, \mathrm{Cd}, \mathrm{Pb}$, and $\mathrm{Se}$ in rice samples by GF AAS. Microchemical Journal, 2016, 124, 402-409, https://doi.org/10.1016/j.microc.2015.09.018.

21. Luna Quinto, M.; Khan, S.; Picasso, G.; Taboada Sotomayor, M.D.P. Synthesis, characterization, and evaluation of a selective molecularly imprinted polymer for quantification of the textile dye acid violet 19 in real water samples. J. Hazard. Mater. 2020, 384, 121374, https://doi.org/10.1016/j.jhazmat.2019.121374.

22. Azizi, A.; Bottaro, C.S. A critical review of molecularly imprinted polymers for the analysis of organic pollutants in environmental water samples. J. Chromatogr. A 2020, 1614, 460603, https://doi.org/10.1016/j.chroma.2019.460603.

23. Barbosa, V.M.P.; Barbosa, A.F.; Bettini, J.; Luccas, P.O.; Figueiredo, E.C. Direct extraction of lead (II) from untreated human blood serum using restricted access carbon nanotubes and its determination by atomic absorption spectrometry. Talanta 2016, 147, 478-484, https://doi.org/10.1016/j.talanta.2015.10.023.

24. Rao,K.; Balaji,T.; Rao, T.; Babu, Y.; Naidu,G.; Determination of Iron, Cobalt, Nickel, Manganese, Zinc, Copper, Cadmium and Lead in Human Hair Inductively Coupled Plasma-Atomic Emission Spectrometry, Spectrochim Acta B 2002, 57, 1333-1338, doi:10.1016/S0584-8547(02)00045-9

25. Si, R.; Han, Y.; Wu, D.; Qiao, F.; Bai, L.; Wang, Z.; Yan, H. Ionic liquid-organic-functionalized ordered mesoporous silica-integrated dispersive solid-phase extraction for determination of plant growth regulators in fresh Panax Ginseng. Talanta 2020, 207, 120247, https://doi.org/10.1016/j.talanta.2019.120247.

26. Peña-Méndez, E.M.; Mawale, R.M.; Conde-González, J.E.; Socas-Rodríguez, B.; Havel, J.; Ruiz-Pérez, C. Metal organic framework composite, nano- $\mathrm{Fe}_{3} \mathrm{O}_{4} @ \mathrm{Fe}($ benzene-1,3,5-tricarboxylic acid) for solid phase extraction of blood lipid regulators from water. Talanta 2020, 207, 120275, https://doi.org/10.1016/j.talanta.2019.120275.

27. Dolan, S.P.; Capar, S.G. Multi-element Analysis of Food by Microwave Digestion and Inductively Coupled Plasma-Atomic Emission Spectrometry. Journal of Food Composition and Analysis 2002, 15, 593-615, https://doi.org/10.1006/jfca.2002.1064.

28. Su, S.; Chen, B.; He, M.; Hu, B. Graphene oxide-silica composite coating hollow fiber solid phase microextraction online coupled with inductively coupled plasma mass spectrometry for the determination of trace heavy metals in environmental water samples. Talanta 2014, 123, 1-9, https://doi.org/10.1016/j.talanta.2014.01.061.

29. Khan, N.; Ryu, K.Y.; Choi, J.Y.; Nho, E.Y.; Habte, G.; Choi, H.; Kim, M.H.; Park, K.S.; Kim, K.S. Determination of toxic heavy metals and speciation of arsenic in seaweeds from South Korea. Food chemistry 2015, 169, 464-470

30. Jinadasa, K.K.; Peña-Vázquez, E.; Bermejo-Barrera, P.; Moreda-Piñeiro, A. Ionic Imprinted Polymer SolidPhase Extraction for Inorganic Arsenic Selective Pre-Concentration in Fishery Products before HighPerformance Liquid Chromatography-Inductively Coupled Plasma-Mass Spectrometry Speciation. J. Chromatogr. A 2020, 1619, 460973, https://doi.org/10.1016/j.chroma.2020.460973.

31. Othman, N.A.F.; Selambakkannu, S.; Azian, H.; Ratnam, C.T.; Yamanobe, T.; Hoshina, H.; Seko, N. Synthesis of Surface Ion-Imprinted Polymer for Specific Detection of Thorium under Acidic Conditions. Polym. Bull. 2020, 78, 165-183, https://doi.org/10.1007/s00289-019-03094-2.

32. Afkhami, F.; Karbassi, A.; Nasrabadi, T.; Vosoogh, A. Impact of oil excavation activities on soil metallic pollution, case study of an Iran southern oil field. Environmental earth sciences 2013, 70, 1219-1224, https://doi.org/10.1007/s12665-012-2208-8.

33. Losev, V.N.; Buyko, O.V.; Trofimchuk, A.K.; Zuy, O.N. Silica sequentially modified with polyhexamethylene guanidine and Arsenazo I for preconcentration and ICP-OES determination of metals in natural waters. Microchemical Journal 2015, 123, 84-89, https://doi.org/10.1016/j.microc.2015.05.022.

34. Khandaker, S.; Chowdhury, M.F.; Awual, M.R.; Islam, A.; Kuba, T. Efficient Cesium Encapsulation from Contaminated Water by Cellulosic Biomass Based Activated Wood Charcoal. Chemosphere 2020, 262, 127801, https://doi.org/10.1016/j.chemosphere.2020.127801.

35. Wen, X.; Wu, P.; Chen, L.; Hou, X. Determination of cadmium in rice and water by tungsten coil electrothermal vaporization-atomic fluorescence spectrometry and tungsten coil electrothermal atomic 
absorption spectrometry after cloud point extraction. Analytica Chimica Acta 2009, 650, 33-38, https://doi.org/10.1016/j.aca.2009.01.053.

36. Kocot, K.; Zawisza, B.; Sitko, R. Dispersive liquid-liquid microextraction using diethyldithiocarbamate as a chelating agent and the dried-spot technique for the determination of $\mathrm{Fe}, \mathrm{Co}, \mathrm{Ni}, \mathrm{Cu}, \mathrm{Zn}, \mathrm{Se}$ and $\mathrm{Pb}$ by energy-dispersive X-ray fluorescence spectrometry. Spectrochimica Acta Part B: Atomic Spectroscopy 2012, 73, 79-83, https://doi.org/10.1016/j.sab.2012.05.003.

37. Dano, M.; Viglašová, E.; Galamboš, M.; Štamberg, K.; Kujan, J. Surface Complexation Models of Pertechnetate on Biochar/Montmorillonite Composite-Batch and Dynamic Sorption Study. Materials 2020, 13, 3108, https://doi.org/10.3390/ma13143108.

38. Zhou, Z.; Liu, X.; Zhang, M.; Jiao, J.; Zhang, H.; Du, J.; Zhang, B.; Ren, Z. Preparation of Highly Efficient Ion-Imprinted Polymers with Fe3O4 Nanoparticles as Carrier for Removal of Cr (VI) from Aqueous Solution. Sci. Total Environ. 2020, 699, 134334, https://doi.org/10.1016/j.scitotenv.2019.134334.

39. Landsberger, S.; Lara, R.; Landsberger, S. Non-destructive determination of uranium, thorium and ${ }^{40} \mathrm{~K}$ in tobacco and their implication on radiation dose levels to the human body. Radiation protection dosimetry 2015, 167, 243-246, https://doi.org/10.1093/rpd/ncv254.

40. Farajzadeh, M.A.; Yadeghari, A. Extraction and preconcentration of nickel, cadmium, cobalt, and lead cations using dispersive solid phase extraction performed in a narrow-bore tube. Journal of industrial and engineering chemistry 2018, 59, 377-387, https://doi.org/10.1016/j.jiec.2017.10.046.

41. Monajjemi, M. Cell membrane causes the lipid bilayers to behave as variable capacitors: A resonance with self-induction of helical proteins. Biophysical Chemistry 2015, 207, 114-127, https://doi.org/10.1016/j.bpc.2015.10.003.

42. Monajjemi, M. Liquid-phase exfoliation (LPE) of graphite towards graphene: An ab initio study. Journal of Molecular Liquids, 2017, 230, 461-472, https://doi.org/10.1016/j.molliq.2017.01.044.

43. Monajjemi, M.; Naderi, F.; Mollaamin, F.; Khaleghian, M. Drug design outlook by calculation of second virial coefficient as a nano study. Journal of the Mexican Chemical Society 2012, 56, 207-211, https://doi.org/10.29356/jmcs.v56i2.323.

44. Monajjemi, M.; Bagheri, S.; Moosavi, M.S. Symmetry breaking of B2N(-,0,+): An aspect of the electric potential and atomic charges. Molecules 2015, 20, 21636-21657,https://doi.org/10.3390/ molecules201219769.

45. Monajjemi, M.; Mohammadian, N.T. S-NICS: An aromaticity criterion for nano molecules. Journal of Computational and Theoretical Nanoscience 2015, 12, 4895-4914, https://doi.org/10.1166/ jctn.2015.4458.

46. Monajjemi, M.; Ketabi, S.; Hashemian, Z.M.; Amiri, A. Simulation of DNA bases in water: Comparison of the Monte Carlo algorithm with molecular mechanics force fields. Biochemistry (Moscow) 2006, 71, 1-8, https://doi.org/10.1134/s0006297906130013.

47. Monajjemi, M.; Lee, V.S.; Khaleghian, M.; Honarparvar, B.; Mollaamin, F. Theoretical Description of Electromagnetic Nonbonded Interactions of Radical, Cationic, and Anionic NH2BHNBHNH2 Inside of the B18N18 Nanoring. J. Phys. Chem C 2010, 114, 15315-15330, https://doi.org/10.1021 /jp104274z.

48. Monajjemi, M.; Boggs, J.E. A New Generation of BnNn Rings as a Supplement to Boron Nitride Tubes and Cages. J. Phys. Chem. A 2013, 117, 1670-1684, http://dx.doi.org/10.1021/jp312073q.

49. Monajjemi, M. Non bonded interaction between BnNn (stator) and BN B (rotor) systems: A quantum rotation in IR region. Chemical Physics 2013, 425, 29-45, https://doi.org/10.1016 /j.chemphys.2013.07.014.

50. Monajjemi, M.; Robert, W.J.; Boggs, J.E. NMR contour maps as a new parameter of carboxyl's OH groups in amino acids recognition: A reason of tRNA-amino acid conjugation. Chemical Physics 2014, 433, 1-11, https://doi.org/10.1016/j.chemphys.2014.01.017.

51. Monajjemi, M. Quantum investigation of non-bonded interaction between the B15N15 ring and BH2NBH2 (radical, cation, and anion) systems: a nano molecularmotor. Struct Chem 2012, 23, 551-580, http://dx.doi.org/10.1007/s11224-011-9895-8.

52. Monajjemi, M. Metal-doped graphene layers composed with boron nitride-graphene as an insulator: a nanocapacitor. Journal of Molecular Modeling 2014, 20, 2507, https://doi.org/10.1007/s00894-014-2507-y.

53. Monajjemi, M.; Heshmat, M.; Haeri, H.H.; Kaveh, F. Theoretical study of vitamin properties from combined QM-MM methods: Comparison of chemical shifts and energy. Russian Journal of Physical Chemistry 2006, 80, 1061-1068, https://doi.org/10.1134/S0036024406070119.

54. Monajjemi, M.; Honaparvar, B.; Khalili Hadad, B.; Ilkhani, A.; Mollaamin, F. Thermo-Chemical Investigation and NBO Analysis of Some anxileotic as Nano- Drugs. African journal of pharmacy and pharmacology 2010, 4, 521-529. https://doi.org/10.33263/BRIAC106.66956705 
55. Monajjemi, M., Najafpour, J., Mollaamin, F. (3,3)4 Armchair carbon nanotube in connection with PNP and NPN junctions: Ab Initio and DFT-based studies, Fullerenes Nanotubes and Carbon Nanostructures 2013, 21(3), pp. 213-232.

56. Monajjemi, M., Jafari Azan, M., Mollaamin, F. Density functional theory study on B30N20 nanocage in structural properties and thermochemical outlook Fullerenes Nanotubes and Carbon Nanostructures, 2013, 21(6), pp. 503-515.

57. Monajjemi, M.; Ghiasi, R.; Ketabi, S.; Passdar, H.; Mollaamin, F. A Theoretical Study of Metal-Stabilised Rare Tautomers Stability: N4 Metalated Cytosine (M=Be2+, Mg2+, Ca2+, Sr2+ and Ba2+) in Gas Phase and Different. Journal of Chemical Research 2004, 1, 11-18, https://doi.org/10.3184/030823404323000648.

58. Monajjemi, M., Baheri, H., Mollaamin, F. A percolation model for carbon nanotube-polymer composites using the Mandelbrot-Given, Journal of Structural Chemistry, 2011, 52(1), pp. 54-59

59. Kumar, S.; Alvero glu, E.; Balouch, A.; Talpur, F.N.; Jagirani, M.S.; Mahar, A.M.; Pato, A.H.; Mal, D.; Lal, S. Fabrication of Chromium-Imprinted Polymer: A Real Magneto-Selective Sorbent for the Removal of $\mathrm{Cr}$ (vi) Ions in Real Water Samples. New J. Chem. 2020, 44, 18668-18678, https://doi.org/ 10.1039/D0NJ04054A.

60. Afkhami, A.; SoltaniM.; Ghaedi, H.; Madrakian, T. Construction of Modified Carbon Paste Electrode for Highly Sensitive Simultaneous Electrochemical Determination of Trace Amounts of Copper (II) and Cadmium (II). Electroanalysis 2016, 28, 296-303, https://doi.org/10.1002/elan.201500308.

61. Elsayed, N.; Alatawi, A.; Monier, M. Diacetylmonoxine Modified Chitosan Derived Ion-Imprinted Polymer for Selective SolidPhase Extraction of Nickel (II) Ions. React. Funct. Polym. 2020, 151, 104570, https://doi.org/10.1016/j.reactfunctpolym.2020.104570.

62. Su, Q.; Deng, L.; Ye, Q.; He, Y.; Cui, X. KOH-Activated Geopolymer Microspheres Recycle Co (II) with Higher Adsorption Capacity than NaOH-Activated Ones. ACS Omega 2020, 5, 23898-23908, https://doi.org/10.1021/acsomega.0c03158.

63. Lee, H.-K.; Choi, J.-W.; Choi, S.-J. Magnetic Ion-Imprinted Polymer Based on Mesoporous Silica for Selective Removal of Co (II) from Radioactive Wastewater. Sep. Sci. Technol. 2020, 1-11, https://doi.org/10.1080/01496395.2020.1797798.

64. Ozturk, E.E.; Bozyigit, G.D.; Buyukpınar, C.; Bakırdere, S. Magnetic Nanoparticles Based Solid Phase Extraction Methods for the Determination of Trace Elements. Crit. Rev. Anal. Chem. 2020, https://doi.org/10.1080/10408347.2020.1797465.

65. Yavir, K.; Konieczna, K.; Marcinkowski, L.; Kloskowski, A. Ionic liquids in the microextraction techniques: The influence of ILs structure and properties. Trends Anal. Chem. 2020, 45, 219-232, https://doi.org/10.1016/j.trac.2020.115994.

66. Murtada, K. Trends in nanomaterial-based solid-phase microextraction with a focus on environmental applications-A review. Trends Envrion. Anal. 2020, 25, 00077, https://doi.org/10.1016/j.teac.2019.e00077.

67. Majda, A.; Mrochem, K.; Wietecha-Posłusznya, R.; Zapotoczny, S.; Zawadzk, M. Fast and efficient analyses of the post-mortem human blood and bone marrow using DI-SPME/LC-TOFMS method for forensic medicine purposes. Talanta 2020, 209, 120533, https://doi.org/10.1016/j.talanta.2019.120533.

68. Napylov, A.; Reyes-Garces, N.; Gomez-Rios, G.; Olkowicz, M.; Lendor, S.; Monnin, C.; Bojko, B.; Hamani, C.; Pawliszyn, J.; Vuckovic, D. In Vivo Solid-Phase Microextraction for Sampling of Oxylipins in Brain of Awake, Moving Rats. Angew. Chem. 2020, 59, 2392-2398, https://doi.org/10.1002/anie.201909430.

69. Kayali-Sayadi, M.N.; Polo-Díez, L.M.; Rios-Acevedo, J.J. On-line HPLC/SPME Interface using dynamic extraction. J. Phys. Conf. Ser. 2020, 1541, 012009, https://doi.org/10.1088/1742-6596/1541/1/012009. 